\title{
A Survey on Underwater Wireless Sensor Networks: Progresses, Applications, and Challenges
}

\author{
J. Premalatha ${ }^{1}$ and Joe Prathap $P \mathrm{M}^{2}$ \\ ${ }^{1}$ Research Scholar, Dept.of CSE, Sathyabama University, Chennai, India. premlatha j@yahoo.com \\ ${ }^{2}$ IT Dept, RMD Engineering College, R.S.M. Nagar, Kavaraipettai, Tiruvallur Dist., India. drjoeprathap@gmail.com.
}

\begin{abstract}
The endangered underwater species always drew the attention of the scientific society since their disappearance would cause irreplaceable loss. Asia is home to some of the most diverse habitats in the earth, but it is estimated that more than one in four species are endangered. In Underwater, a lot of factors are putting marine life under immense pressure. Extreme population pressure is leading to pollution, over-fishing and the devastation of crucial habitats. Consequently, the numbers of almost all fish are declining and many are already endangered. To help these species to survive, their habitat should be strictly protected. This can be achieved by strictly monitoring them. During this course, several parameters, constraints about the species and its environments are focused. Now, advances in sensor technology facilitate the monitoring of species and their habitat with less expenditure. Indeed, the increasing sophistication of underwater wireless sensors offers chances that enable new challenges in a lot of areas, like surveillance one. This paper endorses the use of sensors for monitoring underwater species endangered in their habitat. This paper further examines the key approaches and challenges in the design and implementation of underwater wireless sensor networks. We summarize major applications and the main phenomena related to acoustic propagation, and discuss how they affect the design and operation of communication systems and networking protocols at various layers.
\end{abstract}

\section{Introduction}

The cram of Underwater Wireless Sensor Networks as a research field has grown extensively in recent years offering a huge number of proposal to resolve the communication between the nodes and protocols for information exchange networks[1].

Using wsn networks, we can able to pick a lot of values which is used for new purposes like measuring the relief of the ocean (bathymetry), seafloor shape registering, search for geological resources (i.e. oil, gas, etc.), detecting and tracking fish banks, submarine archaeology, etc[2-4]. These were the main underwater acoustic application mainly use for the exploration of seafloor and fishery with sonar devices. In the 90's the researchers became aware of a new feature applicable to underwater communications, multipoint connections could be capable of translating the networked communication technology to the underwater environment[5-7].

Wireless terrestrial networking technologies have experienced a considerably development in the last fifteen years, not only in the standardization areas but also in the market deployment of a bunch of devices, services and applications. Among all these wireless products, wireless sensor networks are exhibiting an

\footnotetext{
${ }^{2}$ Corresponding author: drjoeprathap@gmail.com.
}

incredible boom, being one of the technological areas with greater scientific and industrial development step[8]. Recently, wireless sensor networks have been proposed for their deployment in underwater environments where many of applications such us aquiculture, pollution monitoring, offshore exploration, etc. would benefit from this technology [9]. Despite having a very similar functionality, Underwater Wireless Sensor Networks (UWSNs) exhibit several architectural differences with respect to the terrestrial ones, which are mainly due to the transmission medium characteristics (sea water) and the signal employed to transmit data (acoustic ultrasound signals)[10].

Then, the design of appropriate network architecture for UWSNs is seriously hardened by the conditions of the communication system and, as a consequence, what is valid for terrestrial WSNs is perhaps not valid for UWSNs. So, a general review of the overall network architecture is required in order tosupply an appropriate network service for the demanding applications in such an unfriendly submarine communication environment.

Major challenges in the design of underwater acoustic networks [11] are:

-Battery power is limited and usually batteries cannot be recharged because solar energy cannot be exploited;

-The available bandwidth is severely limited; 
-The channel suffers from long and variable propagation delays, multi-path and fading problems;

- Bit error rates are typically very high;

-Underwater sensors are prone to frequent failures because of fouling, corrosion, etc.

\section{Communication Architecture}

This section will give an outline of underwater wireless networks going-through all the layers with highlighting on the physical layer and how it behaves in different and changing environment conditions. The topology is a crucial factor in determining the capacity, the energy consumption, and the reliability of a network. Hence, the network topology should be carefully engineered and post-deployment topology optimization should be performed, when possible. A reference architecture for two-dimensional underwater networks is shown in Fig. 1. A collection of sensor nodes are anchored to the underneath of the ocean with deep ocean anchors. Underwater sensor nodes are interconnected to underwater sinks (uw-sinks) by wireless acoustic links. Uw-sinks, as shown in Fig. 1, are network devices in charge of relaying data from the ocean ground network to a surface station. To accomplish this objective, uw-sinks are equipped with two acoustic transceivers, namely a horizontal and a vertical transceiver. The horizontal transceiveris used by the uw-sink to communicate with the sensor nodes in order to: (i) send commands and configuration data to the sensors (uw-sink to sensors); (ii) collect monitored data (sensors to uw-sink). The vertical link is used by the uw-sinks to relay data to a surface station.. The surface station is equipped with an acoustic transceiver that is able to handle multiple parallel communications with the deployed uwsinks [12].

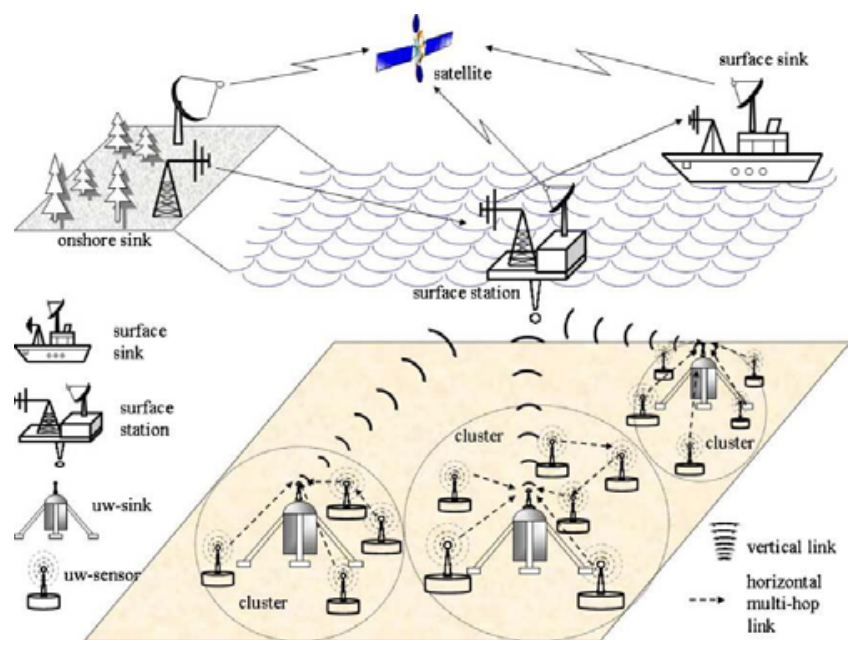

Figure 1. Architecture for 2D UWSN

The typical inner architecture of an underwater sensor is shown in Fig. 2. It consists of a main controller which is interfaced with an oceanographic device or sensor through a sensor interface circuitry. The controller receives data from the sensor and it can store it in the onboard memory, process it, and send it to other network devices by controlling the acoustic modem.

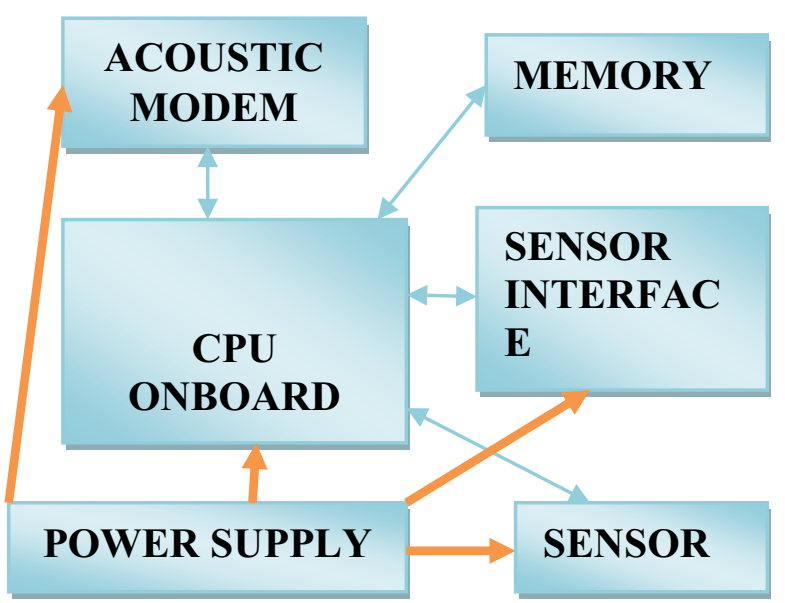

Figure 2. underwater sensor node internal architecture

From the structural design details, the probable challenges related to the operation of low cost, low scale underwater sensors, are listed below:

- It is significant to develop robust, less expensive "nano-sensors",

- It is essential to devise periodical cleaning mechanisms against fouling and corrosion, which may impact the lifetime of underwater devices.

- There is a need for steady, robust sensors on a high range of temperatures since sensor drift of underwater devices may be a concern.

- There is a need for new integrated sensors for synoptic sampling of biological, chemical, and physical parameters to improve the accepting of processes in marine systems.

\section{Ongoing research work}

In Table 1, we report a list of research laboratories and ongoing research projects related to underwater communications and explorations.

Table 1: underwater acoustic sensor networks Research labs and ongoing research projects 


\begin{tabular}{|c|c|c|}
\hline Focus area & $\begin{array}{l}\text { Research } \\
\text { lab/project }\end{array}$ & URL \\
\hline $\begin{array}{l}\text { Acoustic commun. } \\
\text { net for monitoring } \\
\text { underwater } \\
\text { environments in } \\
\text { costal areas }\end{array}$ & ACME & $\begin{array}{l}\text { http://flipper.ncl } \\
\text {.ac.uk/acme/ }\end{array}$ \\
\hline $\begin{array}{l}\text { Applications of } \\
\text { AUVs, platforms } \\
\text { and sensors }\end{array}$ & $\begin{array}{l}\text { Autonomous } \\
\text { Undersea } \\
\text { Systems } \\
\text { Institute } \\
\text { (AUSI) }\end{array}$ & $\begin{array}{l}\text { http://www.ausi. } \\
\text { org/ }\end{array}$ \\
\hline $\begin{array}{l}\text { Underwater } \\
\text { communications }\end{array}$ & $\begin{array}{l}\text { Underwater } \\
\text { Acoustic } \\
\text { Research } \\
\text { Group }\end{array}$ & $\begin{array}{l}\text { http://sonar- } \\
\text { fs.lboro.ac.uk/ }\end{array}$ \\
\hline $\begin{array}{ll}\text { Underwater } & \\
\text { acoustic } & \text { sensor } \\
\text { networks } & \\
\end{array}$ & $\begin{array}{l}\text { BWN-Lab } \\
@ \\
\text { GeorgiaTech }\end{array}$ & $\begin{array}{l}\text { http://www.ece. } \\
\text { gatech.edu/resea } \\
\text { rch//UWASN/ }\end{array}$ \\
\hline $\begin{array}{l}\text { Underwater } \\
\text { acoustic networks }\end{array}$ & $\begin{array}{lr}\text { MIT } \quad \& \\
\text { Woods } & \text { Hole } \\
\text { O.I. } & \\
\end{array}$ & $\begin{array}{l}\text { http://www.mit. } \\
\text { edu/people//rese } \\
\text { arch.html }\end{array}$ \\
\hline $\begin{array}{l}\text { Spatial sampling of } \\
\text { ocean }\end{array}$ & Front Project & $\begin{array}{l}\text { http://www.nop } \\
\text { p.uconn.edu/AD } \\
\text { CPhtml }\end{array}$ \\
\hline $\begin{array}{l}\text { Advanced marine } \\
\text { systems }\end{array}$ & $\begin{array}{l}\text { Ocean } \\
\text { Engineering } \\
\text { a FAU }\end{array}$ & $\begin{array}{l}\text { http://www.oe.f } \\
\text { au.edu/research/ } \\
\text { ams.html }\end{array}$ \\
\hline Sea Grant AUVs & $\begin{array}{l}\text { AUVLab@ } \\
\text { MIT }\end{array}$ & $\begin{array}{l}\text { http://auvlab.mit } \\
\text {.edu/ }\end{array}$ \\
\hline $\begin{array}{l}\text { Underwater } \\
\text { acoustic sensor } \\
\text { networks }\end{array}$ & $\begin{array}{l}\text { Undersea } \\
\text { Seismic } \\
\text { Experimentn } \\
\text { (SNUSE)@ } \\
\text { USC }\end{array}$ & $\begin{array}{l}\text { http://www.isi.e } \\
\text { du/ilense/snuse/ }\end{array}$ \\
\hline $\begin{array}{l}\text { Integrated } \\
\text { sustained ocean } \\
\text { observing } \\
\text { system }\end{array}$ & $\begin{array}{l}\text { Underwater } \\
\text { Technologie } \\
\text { s Laboratory } \\
\text { @Florida }\end{array}$ & $\begin{array}{l}\text { http://my.fit.edu } \\
\text { /swood/subsea.h } \\
\text { tml }\end{array}$ \\
\hline $\begin{array}{l}\text { Adaptive ocean } \\
\text { sampling }\end{array}$ & $\begin{array}{l}\text { Autonomous } \\
\text { Ocean } \\
\text { Sampling } \\
\text { Networks }\end{array}$ & $\begin{array}{l}\text { http://www.prin } \\
\text { ceton.edu/dcsl/a } \\
\text { osn/ }\end{array}$ \\
\hline $\begin{array}{l}\text { Autonomous ocean } \\
\text { sampling networks }\end{array}$ & AOSN & $\begin{array}{l}\text { http://www.mba } \\
\text { ri.org/aosn/ }\end{array}$ \\
\hline $\begin{array}{l}\text { Underwater } \\
\text { acoustics, sonar, } \\
\text { bottom and water } \\
\text { column surveys } \\
\text { with AUVs, signal } \\
\text { processing and } \\
\text { target detection }\end{array}$ & $\begin{array}{l}\text { Underwater } \\
\text { Research } \\
\text { Lab_s } \\
\text { Simon } \\
\text { Fraser } \\
\text { University }\end{array}$ & $\begin{array}{l}\text { http://www.ensc } \\
\text {.sfu.ca/research/ } \\
\text { url/ }\end{array}$ \\
\hline
\end{tabular}

\section{Open issues in layers}

The following Table 2 focuses issues related to various layers which will give clear focus about research ideas.

Table 2:layer wise issues

-In case CDMA is adopted, which we powerfully advocate, it is essential to design access codes with high auto-correlation and low cross-correlation properties to achieve least amount interference among users.

- Research on finest data packet length is needed to maximize the network efficiency.

- It is needed to design low-complexity encoders and decoders to limit the processing power required for forward error correction (FEC) functionalities. Researchers should evaluate the feasibility and the energy-efficiency of nonconvolutional error control coding schemes.

- Distributed protocols should be devised to reduce the activity of a device when its battery is depleting without compromising on network availability.

- Accurate modeling is needed to better realize the dynamics of data transmission at the network layer. Moreover, convincing simulation models and tools need to be developed.

- Algorithms and protocols need to be developed that detect and deal with disconnections due to unforeseen mobility of nodes, failures or battery depletion.

- Local route optimization algorithms are needed to react to consistent variations in the metrics describing the energy efficiency of the underwater channel.

- Mechanisms are needed to integrate AUVs in underwater networks and to enable communication between sensors and AUVs

- In case of geographical routing protocols, it is necessary to devise efficient underwater location discovery techniques.

- For delay-tolerant applications, there is a need to develop mechanisms to handle loss of connectivity without provoking immediate retransmissions.

- It is necessary to devise routing algorithms that are forceful with respect to the intermittent connectivity of acoustic channels. 


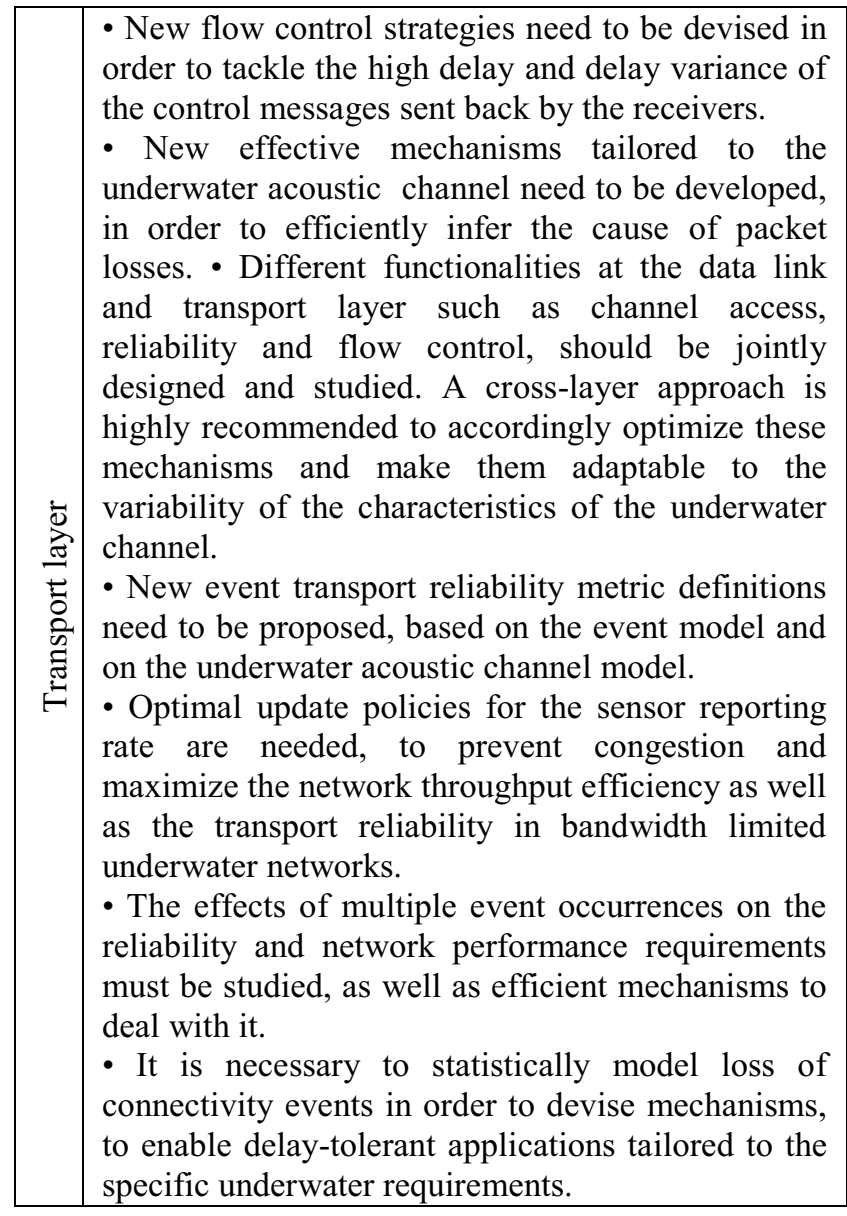

\section{Major Applications}

As mentioned earlier, underwater acoustic wireless sensor networks can be used in a variety of different applications, as it is done by radio frequency air networks[13-15]. The following are some of the major areas:

- Environmental Monitoring. Pollution is nowadays one of the major problems, oil spills from ships or broken tubes can make a lot of harm to the marine biological activity, the industry and tourist places. Monitoring ecosystems can help understanding and predicting the human and climate or weather effect in underwater environment.

- Underwater Navigation. The sensor used to make routing, identifying hazards on the seafloor, rocks or shoals in shallow water,

- Assisted Navigation. Sensors can be placed to identify hazards on the seabed, locate dangerous rocks or shoals in shallow waters, mooring positions and drawing the bathymetry profile of the area.

- Underwater Discovery. Underwater wireless sensor networks can be used to find oilfields or reservoirs, locate routes for placing connections for intercontinental submarine cables. Also they could seek for shipwrecks or archaeology or lost sink cities.

- Prevention of natural disaster. By measuring the seismic activity from different remote location the sensors could alert to the coast places by detecting tsunami or submarine earthquakes alarms.

- Underwater Autonomous Vehicles (UAVs). Distributed sensor in movement can help monitoring area for surveillance, recognition and intrusion detection.

\section{Future Trends}

Using underwater sensor networks a lot of advantages can be achieved, but a lot of research must be done in the upcoming years. The developing of this technology will have a great impact in the industry as well as provide impact in the environment.

It is essential to improve the physical layer performance in terms of efficiency, building low power acoustic modem, reducing the error rate. in the MAC layer, collision avoidance protocols should be adopted.

Distributed CDMA-based schemes are the best candidates for underwater environments, but we should consider the energy consumption factor too. while in the routing layer protocols, one should adapt the changing conditions, to include mobility patterns.

\section{Conclusions}

Underwater Acoustic Wireless Sensor Networks is still budding and following the path of Radio Frequency in Terrestrial Networks. In this article, we provide an overview of the state of the art in underwater acoustic sensor network. We summarized the challenges posed by the peculiarities of the underwater channel with major reference to monitoring applications for the ocean environment. We also analyze characteristics of the underwater channel and outlined future research directions for the growth of effective and trustworthy underwater acoustic sensor networks. The ultimate objective of this article is to encourage and specify the importance of research efforts to lay down fundamental basis for the growth of new advanced communication techniques for efficient underwater communication and networking for improved ocean monitoring and exploration applications.

\section{References}

1. Tunnicliffe, V., Barnes, C. \& Dewey, R. 2008 Major advances in cabled ocean observatories (VENUS and NEPTUNE Canada) in coastal and deep sea settings. In IEEE/OES US/EUBaltic Int. Symp., Tallinn, Estonia, May 2008, pp. 1-7. IEEE.

2. Farr, N., Bowen, A., Ware, J., Pontbriand, C. \& Tivey, M. 2010 An integrated, underwater optical/acoustic communications system. In IEEE Oceans Conf., Sydney, Australia, May 2010, pp. 1-6. IEEE.

3. Vasilescu, I., Kotay, K., Rus, D., Dunbabin, M. \& Corke, P. 2005 Data collection, storage, and 
retrieval with an underwater sensor network. In Proc. 3rd ACM SenSys Conf., San Diego, CA,November 2005, pp. 154-165. ACM.

4. Cella, U. M., Johnstone, R. \& Shuley, N. 2009 Electromagnetic wave wireless communication in shallow water coastal environment: theoretical analysis and experimental results. In Proc.4th ACM Int. Workshop on Underwater Networks (WUWNet), Berkeley, CA, November 2009,pp. 9:1-9:8. ACM.

5. Friedman, J., Torres, D., Schmid, T., Dong, J. \& Srivastava, M. B. 2010 A biomimetic quasistatic electric field physical channel for underwater ocean networks. In Proc. 5th ACM Int. Workshop on Underwater Networks (WUWNet), Woods Hole, MA, September 2010. ACM.

6. Urick, R. 1983 Principles of underwater sound. New York, NY: McGraw-Hill.

7. Stojanovic, M. 2007 On the relationship between capacity and distance in an underwater acoustic communication channel. ACM Mobile Comput. Commun. Rev. 11, 34-43. (doi:10.1145/1347364.1347373)

8. Carrascosa, P. C. \& Stojanovic, M. 2010 Adaptive channel estimation and data detection for underwater acoustic MIMO OFDM systems. IEEE J. Oceanic Eng. 35, 635-646. (doi:10.1109/ JOE.2010.2052326)

9. Roy, S., Duman, T. \& McDonald, V. 2009 Error rate improvement in underwater MIMO communications using sparse partial response equalization. IEEE J. Oceanic Eng. 34, 181201. (doi:10.1109/JOE.2009.2014658)

10. Fairley, P. 2005 Neptune rising. IEEE Spectr. 42, 38-45. (doi:10.1109/MSPEC.2005.1526903)

11. OPNET Modeler v15.0 Reference Manual OPNET Technologies Inc. OPNET Modeler. Available online: http://www.opnet.com (accessed on 12 December 2011).

12. Berkhovskikh, L.; Lysanov, Y. Fundamentals of Ocean Acoustics; Springer: Berlin, Germany, 1982.

13. Peleato, B.; Stojanovic. M. Distance aware collision avoidance protocol for ad hoc underwater acoustic sensor networks. IEEE Commun. Lett. 2007, 11, 1025-1027.

14. Llor, J.; Malumbres, M.P. Performance evaluation of underwater wireless sensor networks with OPNET. In Proceedings of the ACM Simutools. ICST, Barcelona, Spain, 21-25 March 2011.

10. Xie, G.; Gibson, J. Incorporating realistic acoustic propagation models in simulation of underwater acoustic networks: A statistical approach. In Proceedings of MTS/IEEE Oceans Conference, Boston, MA, USA, 18-22 September 2006; pp. 18-21. 